\title{
Os riscos e a promoção do autocontrole na saúde alimentar: moralismo, biopolítica e crítica parresiasta
}

\author{
The risks and the promotion of self-control on nutritional health: \\ morality, biopolitics and parrhesiastic critique
}

Luis David Castiel ${ }^{1}$

Marcos Santos Ferreira ${ }^{2}$

Danielle Ribeiro de Moraes ${ }^{3}$

\footnotetext{
${ }^{1}$ Departamento de Ciências Sociais, Escola Nacional de Saúde Pública, Fundação Oswaldo Cruz. R. Leopoldo Bulhões 1480/827, Manguinhos. 21.041-210 Rio de Janeiro RJ Brasil. luis.castiel@ensp.fiocruz.br ${ }^{2}$ Instituto de Educação Física e Desportos, Centro de Educação e Humanidades, Universidade do Estado do Rio de Janeiro.

${ }^{3}$ Escola Politécnica de Saúde Joaquim Venâncio, Fundação Oswaldo Cruz.
}

\begin{abstract}
This paper deals with proposals for selfcare by means of self-control in the promotion of nutritional health, especially in the quest to avoid weight gain and the consumption of food that does not meet 'healthy food' guidelines. These initiatives present themselves as self-care strategies that are legitimated and enshrined in the context of nutritional heath, linked with moralistic modes on the current ways of leading our lives. The study's critical standpoint adopts a biopolitical approach and 'cynical parrhesia' as an argumentative line of reasoning, which is in line with Cynicism as a philosophical doctrine, subsequently developed by Michel Foucault in his studies on care of the self.

Key words Health promotion, Healthy diet, Care of the self, Risk
\end{abstract}

Resumo O artigo trata das propostas de autocuidado mediante o autocontrole na promoção da saúde alimentar, especialmente nos propósitos de se evitar o ganho de peso e o consumo de comida que não sigam o modelo da 'alimentação saudável. Tais iniciativas se apresentam como estratégias do cuidado de si, legitimadas e naturalizadas no contexto da saúde nutricional, vinculadas a modos moralistas nas formas atuais de se levar a vida. A perspectiva crítica do estudo adota a biopolítica como enfoque teórico e a 'parresia cínica', como linha de argumentação, própria do $\mathrm{Ci}$ nismo como doutrina filosófica, desenvolvida posteriormente por Michel Foucault em seus estudos sobre o cuidado de si.

Palavras-chave Promoção da saúde, Alimentação saudável, Cuidado de si, Risco 


\section{Introdução}

Este trabalho pretende tratar das questões que envolvem as propostas de autocuidado na promoção da saúde alimentar que trazem como foco principal a fórmula do autocontrole, especialmente para evitar ganho de peso e moderar a ingestão de alimentos que não sigam o ideário da 'alimentação saudável'. Tais proposições se apresentam como estratégias do cuidado de si, consagradas e naturalizadas no âmbito da saúde pública e da prevenção de um modo geral.

Aparentemente, de modo esquemático, parece prevalecer no interior dessas concepções uma perspectiva dualista de um possível apelo a uma mente sã que se pauta por análises racionais da existência humana. Estas análises participam da domesticação de corpos potencialmente insanos com seus impulsos nocivos diante das possibilidades de prazer oferecidas pela vida moderna. $\mathrm{O}$ prêmio para este esforço seria alcançar a maior longevidade (com vitalidade) possível.

É preciso situar que isto se dá no interior do capitalismo globalizado neoliberal com seus cânones relativos à liberdade de escolha, direito de decidir e proposições sustentadas pelo individualismo metodológico. Esta perspectiva de entendimento da realidade social considera que os fenômenos sociais são melhor explicados pelas características dos indivíduos compreendidos no fenômeno. Ou seja, toda análise que envolve explicações sociológicas no contexto macro deveria, a priori, ser colocada em termos de explicações no contexto micro dos indivíduos e suas ações.

Em outras palavras, o modelo se configura a partir do sujeito autônomo e responsável capaz de estabelecer relações de custo/benefício (mas que também poderiam ser de ganho/malefício) em suas ações e trocas diante do mundo em que vive. Assim, os indivíduos seriam capazes de eleger o que seria mais adequado para suas necessidades e demandas em função de sua capacidade de atuar efetivamente, uma vez conscientes de suas ações como agentes de consumo em um mercado que oferece múltiplas opções aos consumidores.

Porém, os efeitos adversos deste modelo que não são poucos, nem triviais - muitas vezes implicam na dura face da precarização e sofrimento humano de contingentes excluídos. Uma forma de lidar com estes efeitos indesejáveis se dá através da patologização do mal-estar. Eventualmente se responsabilizam os indivíduos que não sabem se pautar de maneira adequada às dinâmicas de vida estabelecidas socialmente que não assumem de modo explícito sua feição moralista, sobretudo no âmbito da saúde.

Para lidar com esta problemática, adota-se a estratégia analítica de caráter biopolítico que faz uso de conceitos filosóficos da Escola Cínica Helênica - como é o caso da parresia - também abordada por Foucault ${ }^{1}$ ao tratar dos cuidados de si. O estudo enfoca aspectos morais do autocontrole nas proposições de comportamento saudável na alimentação. Nesta perspectiva, são estudados enredos de vídeo de orientação alimentar disponível na internet que estimula o autocontrole e um seriado televisivo de humor que problematiza a questão.

Antes de prosseguir, cabem alguns esclarecimentos sobre o trabalho. Os argumentos deste trabalho pretendem ser ensaísticos, sem pretensão de estabelecer uma análise de cunho sociológico, histórico ou filosófico e as possíveis derivações de sentido dos termos empregados, tarefa complexa que, além disto, ultrapassaria as limitações de espaço para ser publicado. Assim, no decorrer do trabalho, utilizam-se palavras que permitem variações semânticas, inclusive em relação a suas perspectivas teóricas, tais como 'racionalidade,' 'ambiguidade,' individualismo', 'moral', 'ética,' 'moralismo'.

Mesmo assim, acreditamos que há a possibilidade de compreensão do fluxo argumentativo sem ser necessário um despropositado desenvolvimento explicativo que escapa ao contexto de um ensaio com limitações de espaço. E, também, não se coloca, pelo menos neste momento de elaboração, a construção de conceitos-chave na abordagem das questões relativas ao autocontrole baseado na ideia de risco. O referencial contextual no qual a abordagem tenta se situar se refere, ainda que de maneira genérica, ao ambiente da sociedade consumidora ocidental, a exemplo dos ensaios de Zygmunt Bauman sobre esta temática² .

Ainda, convém esclarecer que o recurso de uso de descrição de vídeos pretende servir como ilustrações do autocontrole nos meios de comunicação sem pretensões metodológicas de análise como representação ou amostra de uma determinada sociedade.

\section{Parresia, verdade e crítica}

Importa aqui mencionar que 'parresia' provém do grego 'parrhêsia' [ $\pi \alpha \rho \rho \eta \sigma i ́ \alpha(\pi \alpha \nu=$ todo $+\rho \eta \sigma ı /$ / $\rho \eta \mu \alpha=$ locução/discurso)locução/discurso) $]^{3}$. Era utilizada primordialmente nos escritos de Eurípedes, significando etimologicamente "dizer tudo" e, por extensão, "falar com 
liberdade" e, portanto, "coragem de dizer a verdade" 4 . Cabe ainda designar o termo 'parresiasta' para aquele que pratica a parresia. Entretanto, não é do interesse do presente texto o aprofundamento do estudo do conceito. Mesmo assim, convém indicar que se trata de uma das características do Cinismo como doutrina filosófica. Em termos sucintos, na Grécia antiga, o Cinismo se manifesta como uma crítica ao convencionalismo moral que estabelece regras artificiosas do viver humano e propõe que a autenticidade da ação se dará por intermédio de uma volta a um contexto moral naturalista que assume a animalidade como modelo da conduta (cino - cão) $)^{5}$.

Em síntese, as três características da Escola Cínica são: anaideia - expressão que significa liberdade de ação, desavergonhamento, provocação, irreverência. É o traço que veicula a analogia destes pensadores com os cães; parresia - implica não somente a liberdade de expressão, mas também a responsabilidade de falar a verdade para o bem comum, inclusive enfrentando o perigo pessoal; adiaphoria - significa indiferença às normas sociais, sem preocupações com o que os demais fossem pensar acerca de seus modos de agir e apresentar-se, com atitude desafiadora e provocativa, fora de convencionalismos ${ }^{6}$.

Bauman ${ }^{2}$ considera que as noções de responsabilidade e eleição responsável que se localizavam no terreno semântico da obrigação ética e preocupação moral pelo outro passaram para o território da autorrealização e do cálculo de riscos. De modo que a ideia de responsabilidade apagou o Outro e assumiu o lugar de responsabilidade autorreferida. Aqui, o sociólogo polonês se refere à 'adiaforização' como declaração de que ações carregadas de escolhas morais são eticamente neutras e se apresentam como isentas de avaliações e censuras éticas. A adiaforização é especialmente cabível de ser pensada no âmbito da saúde em termos dos efeitos da abundância de estudos sobre o risco epidemiológico produtores de evidências. Tais evidências determinam práticas preventivas cuja responsabilidade está dirigida a si-próprio, que, por si, envolvem aspectos morais, mas que não costumam assim ser tratados.

Agora, supõe-se que a característica, digamos 'antissocial' do cinismo, tenha influenciado na derivação de sentidos reprováveis socialmente de tal forma que a ideia de cinismo viesse significar "desfaçatez". A virtude cínica residia na simplicidade básica dos atos e costumes, na negação do vínculo a objetos supérfluos e, inclusive, na indiferença em relação a eles. Daí decorre uma in- conclusiva discussão entre o falso e o verdadeiro cinismo onde se vislumbrou uma relação da moral naturalista em enunciados amorais ${ }^{5}$.

Há controvérsias quanto ao fundador da escola ter sido Antístenes. Ferrater-Mora ${ }^{7}$ coloca Diógenes como tal figura. Além disto, há referências ao caráter anedótico de sua obra, o que poderia comprometer seu valor intelectual. Antístenes e Diógenes teriam conduzido a ironia socrática a enunciados plenos de sarcasmo. Já naquela época, este aspecto teria comprometido a 'seriedade' necessária para ser-se um verdadeiro filósofo. Aliás, se discute se, de fato, o cinismo se constituía como uma escola filosófica. De qualquer forma, Ferrater-Mora ${ }^{7}$ assume a dificuldade de escrever-se uma verdadeira história do cinismo.

Para Foucault, a parresia se constituía como uma das técnicas essenciais das práticas de cuidado de si na Antiguidade. Na tradição epicurista, define uma qualidade do médico que sabe da natureza e estabelece a relação entre médico e paciente, ao falar das verdades naturais que podem intervir no modo de ser daquele que está doente. Também, de forma ampliada, se dirige à relação mestre-aluno, no que se refere à atitude moral do mestre e das técnicas de transmissão da verdade ao discípulo, evitando os efeitos da adulação do aluno e a retórica em sua perspectiva persuasiva.

As regras da retórica são distintas das regras da parresia. A parresia consiste em

palavra livre, independente das regras, livre dos procedimentos da retórica, porque ela deve, por um lado, certamente, adaptar-se à situação, à ocasião, às particularidades do auditor; mas sobretudo e fundamentalmente, é uma palavra que, do lado de quem a pronuncia, equivale a um compromisso, equivale a um nexo, constitui um determinado pacto entre o sujeito da enunciação e o sujeito da conduta $[\ldots]^{8}$.

Então, pode-se sintetizar, baseado em Peters ${ }^{9}$, que a parresia possui três funções: - epistêmica, no sentido de enunciar determinadas verdades acerca do mundo; - política, na medida em que se critica as leis e instituições; - terapêutica ou espiritual, que se expressa na ação de delinear a relação entre a verdade e as formas de vida das pessoas.

No caso dos propósitos deste texto, cabe assinalar a parresia cínica como prática daquele que pretende analisar temas que devem ser tratados por teorias críticas, na tentativa de visibilização de outros cenários que tendem a não ser postos em cena, para além das questões de se 
falar a verdade. Até porque precisaremos estabelecer os regimes de verdade que endossamos, uma vez que as evidências empiricistas das ciências da saúde se instituem também como regime de produção de verdades. Então, a parresia consistiria mais propriamente como um recurso no lugar possível da crítica no complexo âmbito sanitário com seus enfoques disciplinares predominantemente biopolíticos.

Ainda, a parresia cínica está ligada a exercícios de humor utilizados para enfatizar aspectos das manifestações paradoxais que nos assolam. A jocosidade se coloca como modo cabível de falar sobre o que pertence ao regime da verdade mesmo no ambiente acadêmico, onde seriedade não deve ser entendida como sisudez. É sabido que o humor subverte significações estabelecidas. Assim, se entende porque os enunciados filosóficos cínicos se explicitavam sob formatos humorísticos.

Então, é possível fazer uso do fato desse estudo analítico ocorrer por caminhos do humor como elemento que permite pertinentes exercícios da crítica. Sobretudo quando ela se mostra aparentemente despropositada e incômoda nos atuais contextos universitários das ciências da saúde preocupados com a produtividade bibliometrizável, sob o primado da ordem simbólica da 'ciência', do modo ritual da 'eficácia instrumental' e da ideologia dominante da 'prática racional' ${ }^{10}$.

Além disto, importa considerar o cinismo numa acepção moderna - como chave analítica crucial para entender as dinâmicas de funcionamento da racionalização em ação nos diversos aspectos do capitalismo atual nas suas correspondentes formas de interação social. Há um modo cínico de operação das estruturas de racionalidade vigentes neste capitalismo.

Em síntese, só é possível haver este modo de racionalização onde se manifestam crises de legitimidade em função dos paradoxos produzidos por um modelo de crescimento econômico e desenvolvimento próprios do novo espírito do capitalismo globalizado contemporâneo ${ }^{5}$ e de seu modelo de acumulação ilimitada do capital por meios formalmente pacíficos ${ }^{11}$.

Este "novo espírito do capitalismo" está à mercê de uma forma generalizada de cinismo configurado pela presença de estruturas normativas duais ${ }^{12}$ que produzem uma pletora de situações da vida cotidiana nas quais acontecem manifestações marcadas acentuadamente pela sensação de ambiguidade. Ou seja, a incorporação ao mesmo tempo de duas racionalidades normativas, que, embora contraditórias, se con- jugam de maneira integrada. Por um lado, estabelecendo regragens das formas de interação social e das metas simbólicas de autorregulação (no nível das normas visando a uma perspectiva de gestão populacional), e por outro, por imperativos comportamentais que ultrapassam as tentativas de estabelecer fronteiras, diante das demandas de satisfação ilimitada (visando a fruição individual sem restrições).

Para a gestão da 'população', esta deve ser concebida, seguindo Foucault, como um 'corpo social' a partir da descrição do que seriam seus processos de interesse representados especialmente por taxas de nascimento e de óbito, duração da vida, produção de riqueza e sua circulação. A totalidade dos processos vitais concretos numa população é o propósito das 'tecnologias de segurança' que se dirigem aos fenômenos de massa das populações para, em tese, prevenir ou compensar pelos perigos e riscos que resultam da existência da população como uma entidade biológica. Os instrumentos aplicados aqui são regulação e controle, mais do que disciplina e supervisão $0^{12}$.

Os objetos da biopolítica não são os seres humanos em suas singularidades, mas suas marcações biológicas mensuradas e agregadas ao nível das populações. Este dispositivo torna possível estabelecer normas, definir padrões e determinar valores médios. A 'vida' se transforma em um elemento independente, objetivo e mensurável, além de se constituir numa realidade prática e epistemologicamente à parte dos seres vivos concretos e das peculiaridades da experiência individual. A noção de biopolítica se relaciona com a emergência de disciplinas como a estatística, demografia, epidemiologia e biologia. Todas estas permitem analisar processos vitais na população e governar indivíduos e coletivos com vistas ao desenvolvimento de correção, exclusão, normalização, disciplina, terapia e otimização $0^{13}$.

O medo de correr riscos e a transformação da segurança se constituem em principais virtudes da sociedade. Isto alimentou uma inclinação a se exagerar os problemas que esta sociedade enfrenta gerando um contexto hiperprevenido e hiperansioso. Este contexto tem reflexos na condução da vida que enfatiza: alta consciência ao risco, predisposição ao pânico, medo ao estranho, suscetibilidade ao abuso/abusadores, preocupação de controle de indivíduos que se descontrolam, que reincidem, que são negligentes em um contexto de fragilização nas relações de confiança ${ }^{14}$. Como se houvesse uma forma de vida compatível com as demandas paradoxais 
do capitalismo, que exigem uma pedagogia para orientar as pessoas a como se movimentar com efetividade em um contexto onde se manifestam paradoxos, contradições e ambivalências.

Ademais, teria havido uma contrarrevolução nos anos 1980/90 - um produto da moralidade conservadora tradicional e do neomoralismo da correção política. Por sua vez, diminui o questionamento aos pressupostos das relações de dominação. Temos, então, uma outra volta do parafuso da correção política no âmbito da saúde em termos de regulação da conduta através do risco - uma 'tecnologia moral' ${ }^{15}$ que participa dessa 'neomoralidade' sanitária que é sustentada pelos: imperativos científicos das evidências empiricistas, especialmente da epidemiologia, e por justificativas éticas sobre o que é bom e mau em termos da relação de cada um com sua saúde, em termos de autocuidado.

Ambos pretendem dar sentido narrativo ao individualismo, mas acabam por isolar e alienar os indivíduos na geração de suas subjetividades e identidades. Em termos breves, as hipóteses quanto às possíveis origens da correção política se localizam em movimentos supostamente da esquerda intelectual acadêmica estadunidense nos anos 1980 contra as discriminações do moralismo tradicional, de suposta inspiração marxista e da escola de Frankfurt. Neste contexto de tempo e lugar, desenvolveu-se um considerável vocabulário moral adequado à tarefa de lutar contra os preconceitos através da crítica cultural. Alguns dos novos termos nomeiam sistemas moralmente preocupantes de dominação: p. ex. racismo, sexismo, classismo, heterossexismo e colonialismo.

O sucesso do neomoralismo se deve ao fato de se dirigir ao indivíduo atomizado e procura dar sentido à sua experiência de isolamento alienado do individualismo contemporâneo através de narrativas individualistas voltadas para a gestão de si-mesmo. Ao mesmo tempo, o neomoralismo tenta reduzir os excessos do capitalismo baseado no consumo e também se mistura com elementos do moralismo tradicional, pois muitos de seus elementos são consistentes com correspondentes preceitos conservadores: idolatria da segurança, ênfase na restrição e moderação, baseados no princípio de precaução, delineado por filósofos dos séculos XIX e $\mathrm{XX}^{14}$.

Esta nova manifestação do individualismo acompanhou a desregulamentação nos anos 1980, com vistas a diminuir a intervenção do Estado para não obstaculizar os fluxos do capital nos mercados globais e nas bolsas de valores: privatização de empresas estatais; afrouxamento dos contratos fixos de trabalho; aumento de oferta de empregos de curta duração, mal remunerados no setor de serviços; queda dos benefícios de seguridade social; substituição de profissionais operacionais por sistemas softwares informáticos; expulsão de indivíduos ativos para o desemprego de longa duração ou aposentadoria, ou mesmo a delinquência ${ }^{16}$.

O fenômeno social traduzido no princípio de precaução levou, igualmente, ao desenvolvimento de uma filosofia da precaução, construída com base em uma história da prudência, que revela, a princípio, o domínio do paradigma da responsabilidade. "Estilo de vida saudável" demanda prevenção total. Pode-se considerar até modalidades de abstinência como defesa supostamente responsável a partir de normas e regras contra aos potenciais vícios/adições propiciados pela moderna vida de consumo.

No terreno do individualismo sanitário, os indivíduos estão constantemente focados em questões relativas à própria segurança ontológica e são compelidos: a seguir recomendações de autocuidado, a adotar comportamentos saudáveis virtuosos, a consumir produtos e expedientes preventivos como fórmula para a desejada vitalidade longeva e a minimizar as manifestações do mal-estar provenientes de aspectos precários dos modos de vida atual.

\section{A promoção do autocontrole na saúde alimentar: vídeo de prevenção do ganho de peso}

Então, esta perspectiva 'parresiasta' permite o exercício crítico dos enunciados de um dos lados da dualidade cínica atual: aquele que enfatiza a contenção e a restrição próprias da promoção do autocontrole na saúde alimentar sustentadas pelos discursos biopolíticos do risco, em consonância com as perspectivas da racionalidade do neoliberalismo paradoxal gerador de ambiguidades.

Por exemplo: a ideia de que a capacidade de resistir a uma tentação pode influenciar 'favoravelmente' muitos aspectos de nossa vida surgiu no fim dos anos 1960, com o psicólogo Walter Mischel, então pesquisador da Universidade de Stanford. Ele decidiu propor um desafio simples a crianças em idade pré-escolar: se elas, sozinhas em uma sala, resistissem por 15 minutos ao impulso de comer um marshmallow, num prato à sua frente, ganhariam um doce extra. Cerca de $30 \%$ dos pequenos voluntários conseguiram ir até o fim do teste - e, até aí, nenhuma grande surpresa. Ela veio quando o pesquisador resol- 
veu checar o que havia acontecido com as mesmas crianças quando elas cresceram. Mischel descobriu que quem conseguira esperar pelo segundo marshmallow era mais bem-sucedido em vários aspectos da vida ${ }^{17}$.

Uma das 'evidências' mais recentes de estudos nesta linha foi resultado de pesquisa feita na Nova Zelândia e publicado em 2011 na revista Proceedings of the National Academy of Sciences of Unites States of America. Os pesquisadores acompanharam 1.000 pessoas até os 32 anos, medindo seu autocontrole de várias maneiras: aplicando questionários, entrevistando pais e professores e os próprios indivíduos. As crianças capazes de moderar seu comportamento se tornaram adultos mais saudáveis, com menor tendência à obesidade, menos casos de doenças sexualmente transmissíveis e até menos cáries nos dentes. Também tinham menos problema com álcool, drogas e dívidas. Enfim, eram aptas a lidar 'responsavelmente', contendo-se diante dos apelos inevitáveis ao consumo desabrido de alimentos ou de outras tentações ${ }^{18}$.

É possível aventar possíveis erros de análise ao não considerar que o 'baixo autocontrole' e o ulterior desfecho social indesejado possam ambos se originar de algum outro fator não levado em conta. No caso, é ingênuo achar que 'ensinar' melhor autocontrole significa assumir que isto irá diretamente afetar os desfechos indesejáveis.

Mas, mesmo assim, parece que o autocontrole é um conceito-chave na perspectiva dos formatos saudáveis para lidar com as tentações pouco salutares sedutoramente oferecidas ao consumo na atualidade. A meta racional que se apresenta faz parte do ideário liberal: liberdade de escolha e capacidade de decisão, desde que bem informada. Ou seja, consuma sempre, mas com moderação e muitos cuidados para evitar o ameaçador potencial adictivante que cada um de nós supostamente carrega no interior de nossos corpos.

Como ilustração, há um portal denominado www.howcast.com - que se apresenta com os "melhores vídeos de 'como fazer' da rede" (the best how to videos on the net) - oferecendo recomendações e receitas dos mais variados tipos para estilo, comida, tecnologia, recreação, aptidão física, saúde, casa, família, dinheiro e educação, relacionamentos e videogames, entre outros diversos tópicos.

No âmbito da saúde e da alimentação, há nesse portal vários vídeos que apresentam diferentes tipos de dietas, por exemplo, 'Como perder peso com cinco dicas secretas', 'Como restringir seu apetite naturalmente', 'Como manter seu estômago com aparência plana (flat)', 'Como perder peso usando as últimas tendências' e 'Como evitar que uma dieta se torne um transtorno alimentar'. Neste artigo, analisamos um vídeo que, de certa forma, serve como emblema dos já citados em termos de temática, pedagogia e desenvolvimento didático, sintomática e apropriadamente denominado 'Como restringir seu apetite naturalmente'.

Neste vídeo de 2 min e $36 \mathrm{seg}$. vemos uma atraente mulher loura, jovem e delgada em cenas de gestão do seu cotidiano; o texto:

É difícil perder peso se você está todo o tempo com fome. Reduza a fissura por comida naturalmente com estas dicas. Você irá precisar de: óleo de hortelã-pimenta, oito horas de sono por noite, uma dieta rica em fibras, exercício aeróbico, comidas que dão sensação de preenchimento e goma de mascar. Opcional: caminhadas de 15 minutos e comidas crocantes. Passo 1: inale levemente o óleo de hortelã-pimenta antes da refeição. Participantes de estudo que assim fizeram comeram $3000 \mathrm{ca}$ lorias totais menos de gorduras e carboidratos cada semana, relatando que seu nivel de fome se reduziu dramaticamente depois da inalação do aroma. $O$ óleo essencial de hortelã-pimenta está disponivel em lojas de alimentos saudáveis; Passo 2: tenha como meta oito horas de sono todas as noites. Pessoas que tiveram todas essas horas de sono têm niveis mais elevados do hormônio leptina, um depressor do apetite. Por outro lado, pessoas privadas de sono têm níveis mais elevados do hormônio grelina que diz ao cérebro que você está com fome; Passo 3: Procure um modo de alimentar-se de modo consciente [ênfase nossa], que significa comer lentamente e considerar depois de cada bocado se você ainda está com fome ou não. De acordo com a Associação Dietética Americana, pode tardar $20 \mathrm{mi}$ nutos para seu cérebro enviar um sinal para seu estômago dizendo que está cheio, então confira seu corpo à medida em que come para evitar comer em demasia; Passo 4: coma mais fibras. Isto te mantém mais cheia por mais tempo. Em um estudo participantes que comeram 14 gramas extras de fibra por dia consumiram 10\% menos de calorias diárias do que aqueles que comeram menos fibras; Passo 5: Faça exercícios aeróbicos. Pessoas que o fazem desenvolvem níveis mais elevados de uma proteina sanguínea chamada fator neurotrófico derivado do cérebro que se crê que suprime o apetite. Caminhar por 15 minutos ajuda a diminuir a fissura por chocolates de acordo com um estudo; Passo 6: Coma alimentos que a façam sentir-se cheia mais rapidamente e por mais tempo. De acordo com pesquisa, incluem-se batatas cozidas, laranjas, 
maçãs, peixe, massas de farinha integral, nozes, carne, feijão cozido, uvas, pão integral, abóbora e abacate. Escolha comidas crocantes. Pesquisas mostram que quanto mais tempo para mastigar sua comida, menos calorias totais você irá consumir; Passo 7: Masque chicletes depois das refeições. Em um estudo, pessoas que mascaram chicletes depois do almoço comeram menos lanches durante a tarde e sentiram menos fissuras por doces que pessoas que não fizeram deste modo. Você sabia que fissuras por comidas e por drogas que um adicto sente vêm da mesma parte do cérebro ${ }^{19}$

Praticamente o vídeo propõe protocolos comportamentais, visando uma vigilância constante, em geral, descontextualizada das contingências da vida que se leva, em busca da moderação de apetites e prazeres diante de fatores aparentemente triviais que conspiram a favor de adições/vícios que podem levar ao ganho de peso indesejável e nocivo. Tudo isto devidamente baseado em uma fórmula que alia evidências de estudos científicos e juízos morais implícitos sobre o que é correto na gestão baseada no autocontrole da existência de cada um.

A recomendação assinalada de "alimentar-se de modo consciente" (mindful eating) ${ }^{20}$ refere-se a uma proposta que assume um formato contemplativo no ato de ingerir comida como recurso para desenvolver autocontrole na alimentação. Há um portal do Centro para a Alimentação Consciente (http://www.tcme.org) que segue, em síntese, uma orientação que mescla rituais alimentares com traços religiosos das virtudes cardeais cristãs como a temperança, fortaleza e prudência no ato de comer.

Isto se dá em um contexto de certa forma aparentado ao movimento que se convencionou chamar popularmente new age. Assim, agrega teorias holísticas que apregoam a experiência singular com os próprios alimentos sem julgamentos, mediante escolhas individuais que incluem 'todos' os aspectos envolvidos no ato de comer. Este deve ocorrer de forma atenta e focada, sem aparentemente preocupar-se com desfechos de saúde resultantes, mas, tendo em conta os efeitos deletérios da alimentação sem consciência. Ao mesmo tempo, também deve-se procurar alcançar determinados objetivos específicos em termos de saúde, à medida em que a experiência de comer se torna cada vez mais vinculada às sensações de saúde. E, claro, seus vínculos com os alimentos, outros seres viventes e a mãe-terra ${ }^{21}$.

O breve ideário dos princípios da proposta é elucidativo ao explicar em que consiste a alimentação consciente. Em síntese, parece tratar-se de estratégias que não deixam de propor o autocontrole baseado em pressupostos e disposições baseadas em narrativas e rituais ordenadores:

permitir-se estar consciente das oportunidades positivas e nutritivas disponíveis através da preparação e consumo da comida com relação à nossa própria sabedoria; escolher comer alimentos que são tanto prazerosos para você e nutritivos para seu corpo, empregando todos os seus sentidos para explorar, saborear e degustar; reconhecer respostas à comida (gosta, indiferente, desgosta) sem julgamento; experienciar estar consciente das indicações de fome física e saciedade para orientar sua decisão de começar e parar de comer ${ }^{21}$.

Seguindo a perspectiva do autocontrole, cabe trazer à cena um dos ideólogos da sua importância na vida atual através do exercício da força de vontade: o psicólogo e pesquisador estadunidense Roy F. Baumeister, da Florida State University, que com John Tierney escreveu o livro 'Força de Vontade. A redescoberta do poder humano'.

Em linhas gerais, os autores consideram que a maioria dos problemas que afeta os indivíduos modernos - adição, comer em excesso, crime, violência doméstica, doenças sexualmente transmissíveis, preconceito, gravidez indesejada, dívidas, fracasso educacional, fraco desempenho escolar, falta de recursos em poupança, dificuldade em exercitar-se - reflete algum grau de falha no autocontrole como aspecto central. A psicologia teria identificado duas características principais que parecem produzir grandes benefícios: a inteligência e o autocontrole. Se não há como sustentar de forma duradoura aumentos na inteligência, o autocontrole pode ser fortalecido ${ }^{22}$.

Tanto o enredo do vídeo como o livro servem como emblemas de autocuidado mediante autocontrole de acordo com o 'espírito da época' dominante e seguem a mesma retórica de produção de narrativas para dar conta da experiência do individualismo que isola e aliena. Ambos dão receitas objetivas de como fiscalizar racionalmente nossos corpos-máquinas bioquímicas - capazes de sair de nosso controle - para perder e manter o peso de modo disciplinado. Tudo isto em nome da longevidade, por meio de recomendações em nome da saúde, a ponto de chegar a ocupar um lugar passível de pregação moralista.

Como um exercício de parresia cínica, ilustramos os conteúdos e as receitas dos vídeos citados e as afirmações e pressupostos altamente discutíveis e conservadores do livro acima mencionado com um seriado televisivo estadunidense, também exibido nas redes brasileiras de televisão. 


\section{A teoria do Big Bang e a imortalidade como exercício parresiasta diante do moralismo sanitário}

A comédia e seriado "The Big Bang Theory" estreou em 2007 nos Estados Unidos e logo teve êxito. Os criadores da série são Chuck Lorre e Bill Prady. A comédia de situações mostra o relacionamento entre os colegas 'nerds' [palavra que na língua inglesa se origina de uma gíria estudantil, provavelmente uma corruptela da gíria dos anos 1940 'nert', que significa 'pessoa estúpida ou maluca', por sua vez, corruptela de 'nut' (louco $)^{23}$ ] que dividem um mesmo apartamento, Leonard e Sheldon, físicos acadêmicos, e a atraente vizinha de andar, Penny, que trabalha como garçonete. Leonard e Sheldon costumam ser visitados por dois amigos e também companheiros de trabalho na Universidade, Rajesh e Howard, e todos se dedicam em seu tempo livre a diversões especializadas 'nerd'.

No segundo episódio da quarta temporada de 2010, chamado 'A amplificação do vegetal crucífero', o personagem Sheldon chega à conclusão de que a tecnologia necessária para transplantar sua mente para um robô será inventada pouco depois de sua morte, dentro dos cálculos compatíveis com sua expectativa de vida. Assim, decide adotar um comportamento saudável com correspondentes medidas nutricionais, como uma dieta com vegetais crucíferos - uma maneira de prolongar sua longevidade para chegar à tecnologia de 'imortalidade'.

Sua primeira refeição dietética consiste apenas em um prato de couve-de-bruxelas. Mais tarde, à noite, Sheldon começa a passar mal com dores abdominais e vai despertar o amigo Leonard para levá-lo a um hospital. Apresenta a ele várias hipóteses diagnósticas absurdas pesquisadas na internet, mas, este, mais realista, desconfia que pode ser uma apendicite. Antes de sair de casa, é surpreendido por uma manifestação corporal que o leva a concluir que se trata, tão somente, de excesso de gases intestinais. O episódio segue por outros rumos e, por fim, Sheldon desiste da dieta.

O título do episódio se deve ao fato da ocorrência da 'amplificação' de um vegetal crucífero (suas flores têm quatro pétalas em forma de cruz) como é o caso da couve-de-bruxelas - assim como de outros vegetais saudáveis, como repolho, brócolis, couve, couve-flor, nabo, agrião, rabanete, repolho, mostarda. Há estudos epidemiológicos com este grupo de vegetais, ricos em glicosinolatos, que teriam comprovada sua ação preventiva contra cânceres de pulmão e estômago ${ }^{24}$.
Então, nada mais 'racional' para alguém como Sheldon que uma dieta crucífera serviria para ampliar seu tempo de vida para alcançar a longevidade suficiente para obter a imortalidade robótica. De certa forma, uma caricatura de algo que é apregoado implicitamente pelos discursos preventivos de autocuidado: prolongar a vida para ser-se mais longevo possível, como possibilidade daqueles que podem atuar com os eventuais custos de tal modalidade de consumo.

Aqui, podemos repetir que se trata de um exercício parresiasta cínico em sua vertente humorística, diante da crítica ao moralismo cada vez mais vigente na saúde. Independentemente disto, a iniciativa caricatural ainda pertencente ao terreno da ficção científica - próprio de alguém com as peculiaridades e modo de ser de Sheldon.

A ciência e a tecnologia se apresentam como instâncias cruciais para compreender as experiências de vida e a produção de normatividades relacionadas aos processos de saúde/adoecimento das pessoas idosas. Tal contexto inclui produtos farmacêuticos, aparelhos auxiliares para as dificuldades de locomoção, telefones celulares, uma vez que estes objetos técnicos entram em interação constante com idosos. E, quem sabe, algum dia existam robôs com memória onde possa ser armazenada a 'nossa memória'...

Seria ainda cabível considerar, em relação ao medo de ganhar peso, o contexto de ansiedades sobre o risco, tal como assinala Crawford ${ }^{25}$, ao considerar que o moderno 'imperativo da saúde 'é identificar perigos para controlá-los. As questões centrais nas ideologias de saúde que se colocam são: a) circunscrever que riscos e que formas de controle - se individuais (especialmente enfatizados), corporativos ou governamentais; b) o nível apropriado de controle. Parece haver uma defasagem cada vez maior em relação às percepções de perigo e a efetividade das práticas - políticas, médicas ou pessoais - para lidar com tal situação.

\section{Considerações finais}

A questão atual relativa ao medo de engordar chama a atenção para as dimensões morais do problema, assim como faz a perspectiva da ansiedade excessiva diante do risco e da demanda pelo respectivo autocontrole na ingesta. De todas as formas, a relação da promoção da saúde alimentar com o ganho de peso tende a se inscrever no âmbito dos tratamentos morais que acom- 
panham o mal-estar na civilização capitalista globalizada e a correspondente racionalidade cínica na operação de suas estruturas normativas duais que simultaneamente estimulam e restringem. As pessoas, de um modo variável, não passam incólumes às precarizações e aos sofrimentos provocados por este panorama.

Enfim, importa aqui, ao finalizar, enfatizar que há sentido na busca de falar-se a verdade em termos de parresia, mesmo sem estar baseado em evidências empiricistas. Pois estas, como vimos, ocupam uma posição adiaforizante, ou seja, parecem indiferentes quanto à sua responsabilidade em função das implicações morais resultantes das dinâmicas de sua utilização social.

Inclusive, vale a perspectiva trazida por Foucault, ao considerar o ato parresiasta de se dizer a 'verdade' - sobretudo no sentido de manter a perspectiva crítica em nome dela. Esta seria uma das formas para poder se questionar os contextos contemporâneos de dominação que acompanham a produção tecnocientífica em sua relação com a produção de subjetividades nas sociedades.

$\mathrm{Na}$ verdade, temos uma tarefa no âmbito moral, qual seja, a de atuar na busca de outros compromissos ético-políticos que se afastem da perspectiva utilitária dos agentes supostamente autônomos e racionais, com direito de decidir e escolher seus próprios benefícios diante dos cus- tos estipulados - só que dentro de possibilidades bastante reduzidas e afastadas de dimensões emancipatórias. Neste sentido se configura como uma contribuição para abordar a dinâmica das relações de poder na sociedade que modelam as relações que se manifestam no contexto das práticas pessoais e coletivas em saúde que interagem com as dimensões subjetivas dos indivíduos ${ }^{26}$.

Há necessidade de análise crítica dos modos opressores produzidos pela racionalidade cínica que se naturalizam e que sustentam a demanda pelo enfrentamento dos modos de sujeição subjetiva. Isto aparece, por exemplo, no uso de selos de aprovação como alimento saudável por parte de sociedades científicas no âmbito da saúde em vários alimentos industrializados. A saúde, por esses caminhos, fica reduzida a um ideal de inexistência de patologias, a alimentação tratada como técnica de evitação de doenças e a vida humana subordinada às normas estabelecidas por técnicos especialistas ${ }^{27}$. Assim, se legitima e se normatiza de modo cinicamente 'institucionalizado' por experts o alimento como medicamento. Como procuramos apresentar, importa estar atento aos jogos de interesse e de poder e resistir ao tratamento moralista dos riscos à saúde através da normatividade restritiva da promoção da saúde alimentar voltada para uma ideia exacerbada socioculturalmente de controle do peso.

\section{Colaboradores}

LD Castiel, MS Ferreira e DR Moraes participaram igualmente de todas as etapas de elaboração do artigo. 


\section{Referências}

1. Foucault M. Fearless Speech. In: Pearson J, organizadores. Fearless Speech. Los Angeles: Semiotext (e); 2001.

2. Bauman Z. Vida para consumo: a transformação das pessoas em mercadorias. Rio de Janeiro: Jorge Zahar; 2008.

3. Saxonhouse AW. Free speech and democracy in ancient Athens. Ann Arbor: Cambridge University Press; 2005.

4. Belo F, Andrade PGG. Foucault, Direito e Parresia: Um projeto de pesquisa. In: Congresso Nacional do CONPEDI; 2007; Belo Horizonte. p.6186-6205.

5. Safatle V. Cinismo e Falência da Crítica. São Paulo: Boitempo Editorial; 2008.

6. Reale G, Antiseri D. Filosofia pagã antiga. In: Reale G, Antiseri D, organizadores. História da filosofia. São Paulo: Paulus; 2003.

7. Ferrater-Mora J. Diccionario de filosofía. Madrid: Alianza Editorial; 1986.

8. Castro E. Vocabulário de Foucault: um percurso pelos seus temas, conceitos e autores. Belo Horizonte: Autêntica; 2009.

9. Peters MA. Truth-telling as an educational practice of the self: Foucault, Parrhesia and the ethics of subjectivity. Oxford Rev Educ 2003; 29(2):207-223.

10. Comaroff J. Medicine: symbol and ideology. In: Wright $\mathrm{P}$, Treacher A, organizadores. The problem of medical knowledge. Edinburgh: Edinburgh University Press; 1982. p. 49-68.

11. Boltanski L, Chiapello Ė. O novo espírito do capitalismo. Rio de Janeiro: Martins Fontes; 2009.

12. Zizek S. Eles não sabem o que fazem - O sublime objeto da ideologia. Rio de Janeiro: Jorge Zahar; 1992.

13. Lemke T. Biopolitics: An advanced introduction. New York: New York Univesity Press; 2011.

14. Furedi F. Culture of fear revisited: risk-taking and the morality of low expectation. London: Continuum Books; 2006.

15. Lupton D. Risk. New York: Routledge; 1999.

16. Türcke C. Sociedade excitada: filosofia da sensação. Campinas: Editora Unicamp; 2010.

17. Lehrer J. Don't! The secret of self-control. The New Yorker 2009 mai 18. [Internet]. [acessado 2012 out 11]. Disponível em: http://www.newyorker.com/ reporting/2009/05/18/090518fa_fact_lehrer?current Page $=$ all
18. Moffitt TE, Arseneault L, Belsky D, Dickson N, Hancox RJ, Harrington H, Houts R, Poulton R, Roberts BW, Ross S, Sears MR, Thomson WM, Caspi A. A gradient of childhood self-control predicts health, wealth, and public safety. Proc Natl Acad Sci USA 2011; 108(7):2693-2698.

19. Howcast. How to curb your appetite naturally. [Internet]. [acessado 2012 out 11]. Disponível em: http:/ /www.youtube.com/watch?v=Yb9kbTYxsR0.

20. Chozen-Bays J. Mindful Eating: a guide to rediscovering a healthy and joyful relationship with Food. Boston: Shambhala Publications; 2009.

21. The Center for Mindful Eating. Principles. [Internet]. [acessado 2012 out 11]. Disponível em: http:/ /www.tcme.org/principles.htm.

22. Baumeister RF, Tierney J. Força de Vontade: a redescoberta do poder humano. São Paulo: Lafonte-Larousse; 2012.

23. Harper D. Online Etymology Dictionary. [Internet]. [acessado2012 set 27]. Disponível em: http:// www.etymonline.com/index.php?term=nerd.

24. Kim MK, Park JHY. Cruciferous vegetable intake and the risk of human cancer: epidemiological evidence. Proc Nutr Soc 2009; 68(1):103-110.

25. Crawford R. Risk ritual and the management of control and anxiety in medical culture. Health 2004; 8(4):505-528.

26. Carvalho SR, Gastaldo D. Promoção à saúde e empoderamento: uma reflexão a partir das perspectivas crítico-social pós-estruturalista. Cien Saude Colet 2008; 13(Supl. 2):2029-2040.

27. Villagelim ASB, Prado SD, Freitas RF, Carvalho MCVS, Cruz CO, Klotz J, Freire GB. A vida não pode ser feita só de sonhos: reflexões sobre publicidade e alimentação saudável. Cien Saude Colet 2012; 17(3):681-686.

Artigo apresentado em 20/03/2013

Aprovado em 28/04/2013

Versão final apresentada em 06/05/2013 